\title{
Synthesis and characterization of bisphenol sodium complexes: An efficient catalyst for the ring-opening polymerization of L-lactide
}

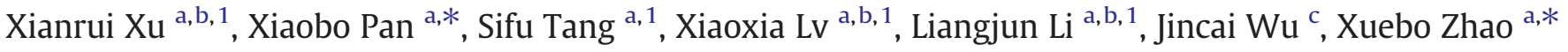 \\ a Qingdao Institute of Bioenergy and Bioprocess Technology, Chinese Academy of Sciences, People's Republic of China \\ b University of Chinese Academy of Sciences, Beijing, 100049, Beijing, People's Republic of China \\ c Key Laboratory of Nonferrous Metal Chemistry and Resources Utilization of Gansu Province, College of Chemistry and Chemical Engineering, Lanzhou University, Lanzhou 730000, \\ People's Republic of China
}

\section{A R T I C L E I N F O}

\section{Article history:}

Received 17 November 2012

Accepted 21 December 2012

Available online 8 January 2013

Keywords:

Sodium complexes

Catalyst

Ring opening polymerization

Polydispersity indexes

\begin{abstract}
A B S T R A C T
Two sodium complexes, $\left[\left(\mu_{3}-\mathrm{MDBP}\right) \mathrm{Na}_{2}(\mathrm{THF})_{2}\right]_{2}\left[\left(\mu_{3}-\mathrm{OCH}_{2} \mathrm{CH}_{2} \mathrm{OCH}_{3}\right) \mathrm{Na}_{2}(\mathbf{1})\right.$ and $\left[\left(\mu_{1}-\mathrm{MDBP}\right) \mathrm{Na}\left(\mu_{2}-\mathrm{H}_{2} \mathrm{O}\right)\right.$ $(\mathrm{THF})]_{2}(\mathrm{THF})_{2}(\mathbf{2})$ have been synthesized and structurally characterized. Experimental results show that complex 1 initiates efficiently the ring opening polymerization of L-lactide in a controlled fashion, yielding polymers with narrow polydispersity indexes in a wide range of monomer-to-initiator ratios.
\end{abstract}

(c) 2013 Elsevier B.V. All rights reserved.
Currently, polyesters such as polylactide (PLA) and poly $(\varepsilon-$ caprolactone) (PCL) are of the most important synthetic biodegradable and biocompatible polymers due to their wide range of biomedical and pharmaceutical applications such as controlled drug delivery, resorbable sutures, medical implants, and scaffolds for tissue engineering [1]. An effective method for the synthesis of PLA and PCL is the ring-opening polymerization (ROP) of related cyclic esters, [2] where metal alkyls, [3] amides, [4] thiolates, [5] aryl oxides, [6] alkoxides [7] and enolates [8] in the presence or absence of alcohol have been used as initiators. Among them, single-site metal alkoxides have the highest activity with a good control over the polymer molecular weight [7].

Metal complexes supported by a variety of ligands such as bisphenol, $\beta$-diketiminate, salen, and many others have been developed and used as catalytic/initiating systems for ROP of lactide. And many metal complexes, such as lithium, sodium, magnesium, aluminum, zinc, stannous and trivalent lanthanide derivatives [9] have been reported to be effective initiators of ROP of lactones/lactides giving polymers with both high molecular weights and high yields. However, the cytotoxicity and difficulties in removal of the catalyst from the resulting polymer have limited their utilization when a medical-grade polymer is required. Among these metals, sodium is non-toxic and essential for human life, [10] therefore, sodium complexes are good candidates as catalysts/initiators in the preparation of biomedical grade PLA. However, the reactivity of sodium complexes [11] has barely received

\footnotetext{
* Corresponding authors. Tel.: + 86532 80662728x9; fax: + 8653280662728 .

E-mail addresses: panxb05@hotmail.com (X. Pan), zhaoxb@qibebt.ac.cn (X. Zhao).

1 Tel.: + 86532 80662728x9; fax: + 8653280662728 .
}

attention. Here, we report synthesis, characterization two novel sodium complexes $\left[\left(\mu_{3}-\mathrm{MDBP}\right) \mathrm{Na}_{2}(\mathrm{THF})_{2}\right]_{2}\left[\left(\mu_{3}-\mathrm{OCH}_{2} \mathrm{CH}_{2} \mathrm{OCH}_{3}\right) \mathrm{Na}_{2}\right.$ (1) and $\left[\left(\mu_{1}-\mathrm{MDBPH}\right) \mathrm{Na}\left(\mu_{2}-\mathrm{H}_{2} \mathrm{O}\right)(\mathrm{THF})\right]_{2}(\mathrm{THF})_{2}(\mathbf{2})$. And the catalytic activity of complex 1 towards ROP of L-lactide is investigated. As we expected, the complex $\mathbf{1}$ is a potential initiator for ring-opening polymerization of lactide, which was confirmed by the experiment results.

The unusual sodium aggregate, $\left[\left(\mu_{3}-\mathrm{MDBP}\right) \mathrm{Na}_{2}(\mathrm{THF})_{2}\right]_{2}\left[\left(\mu_{3}-\mathrm{OCH}_{2}\right.\right.$ $\left.\mathrm{CH}_{2} \mathrm{OCH}_{3}\right) \mathrm{Na}_{2}$ (1), was obtained as a white crystalline solid in $73 \%$ yield from the reaction of 6,6'-methylenebis(2,4-di-tert-butylphenol) $\left(\mathrm{MDBP}-\mathrm{H}_{2}\right)$ with $3.5 \mathrm{M}$ equiv of sodium and $1 \mathrm{M}$ equiv of 2 methoxyethanol in toluene, followed by the removal of solvent and crystallization from THF/hexane $(10 \mathrm{~mL}: 30 \mathrm{~mL})$ as shown in Scheme 1 . The ${ }^{1} \mathrm{H}$ NMR spectrum (toluene- $d_{8}$ ) signals for the corresponding aromatic rings, methylene group, 2-methoxyethanolate, as well as the tert-butyl and protons of THF appeared at 7.82, 7.29 $(\mathrm{Ar}-\mathrm{H}), 5.26,3.44\left(\mathrm{Ar}-\mathrm{CH}_{2}-\right), 4.03,3.26,2.78\left(\mathrm{O}-\mathrm{CH}_{2} \mathrm{CH}_{2} \mathrm{OCH}_{3}\right), 1.51$, 1.48 (t-Bu), and 3.20, 1.30 (THF), respectively, supporting the identical chemical environments of these groups and structure of the complex 1. During preparation of complex $\mathbf{1}$, complex $\mathbf{2}$ shows an interesting structure of $\left[\left(\mu_{1}-\mathrm{MDBPH}\right) \mathrm{Na}\left(\mu_{2}-\mathrm{H}_{2} \mathrm{O}\right)(\mathrm{THF})\right]_{2}(\mathrm{THF})_{2}$ which was obtained unexpectedly maybe due to trace water in the reaction solvent. Subsequently, complex $\mathbf{2}$ was prepared as colorless crystalline solid through two different approaches. The ${ }^{1} \mathrm{H}$ NMR spectra and microanalyses of complex 2 are consistent with our expectations. Their molecular structures and coordination modes have been further verified by X-ray diffraction studies.

The crystal of complex $\mathbf{1}$ was obtained from a saturated solution in THF/hexane and only weakly diffracting, which led to a high $\mathrm{R}$ factor. Complex $\mathbf{1}$ is crystallized in orthorhombic space group Pbca. The 
<smiles>CC#CC(C)(C)C</smiles><smiles>CC(C)(C)Cc1cc(C(C)(C)C)cc(Cc2cc(C(C)(C)C)cc(C(C)(C)C)c2O)c1O[Nb](O)(Oc1c(Cc2cc(C(C)(C)C)cc(C(C)(C)C)c2O)cc(C(C)(C)C)cc1CC(C)(C)C)Oc1c(CC(C)(C)C)cc(C(C)(C)C)cc1CC(C)(C)C</smiles>

2

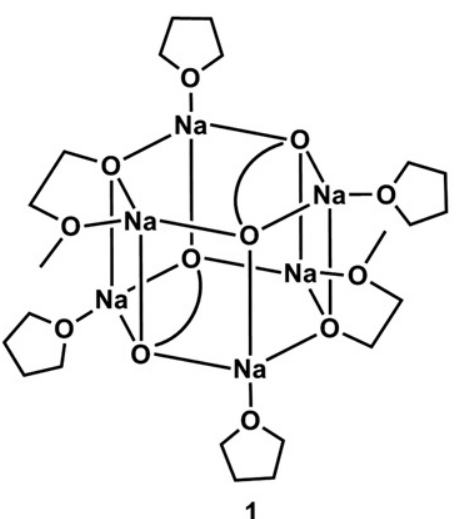

Reaction conditions:

(i) sodium, 2-methoxyethanol, toluene;

THF/hexane, re-crystallization

(ii) sodium hydroxide, toluene;

THF/hexane, re-crystallization

Scheme 1. Preparation of complexes $\mathbf{1}$ and $\mathbf{2}$.

asymmetric unit is composed of three independent Na centers, one $\mathrm{MDBP}^{2-}$ ligand, one 2-methoxyethanolate group, and two coordinated THF molecules in a crystal lattice. As shown in Fig. 1, there are three different $\mathrm{Na}$ atoms in the asymmetric unit of $\mathbf{1}$. Na1 is coordinated by four oxygen atoms $(01,02,03$, and 06$)$ from three different ligands with $\mathrm{Na} 1-\mathrm{O}$ bond lengths ranging from 2.241(5) to 2.352(6) $\AA$, and the $\mathrm{O}-\mathrm{Na} 1-\mathrm{O}$ bond angles varying from $92.78(15)$ to $122.08(19)^{\circ}$. $\mathrm{Na} 2$ is four-coordinated with distorted tetrahedral environment by two oxygen atoms (O1A and 02) from two different MDBP ligands and two oxygen atoms ( $\mathrm{O} 3$ and $\mathrm{O} 4$ ) from one 2-methoxyethanolate group. The Na2 - O bond lengths extend from 2.264(5) to 2.305(7) $\AA$,

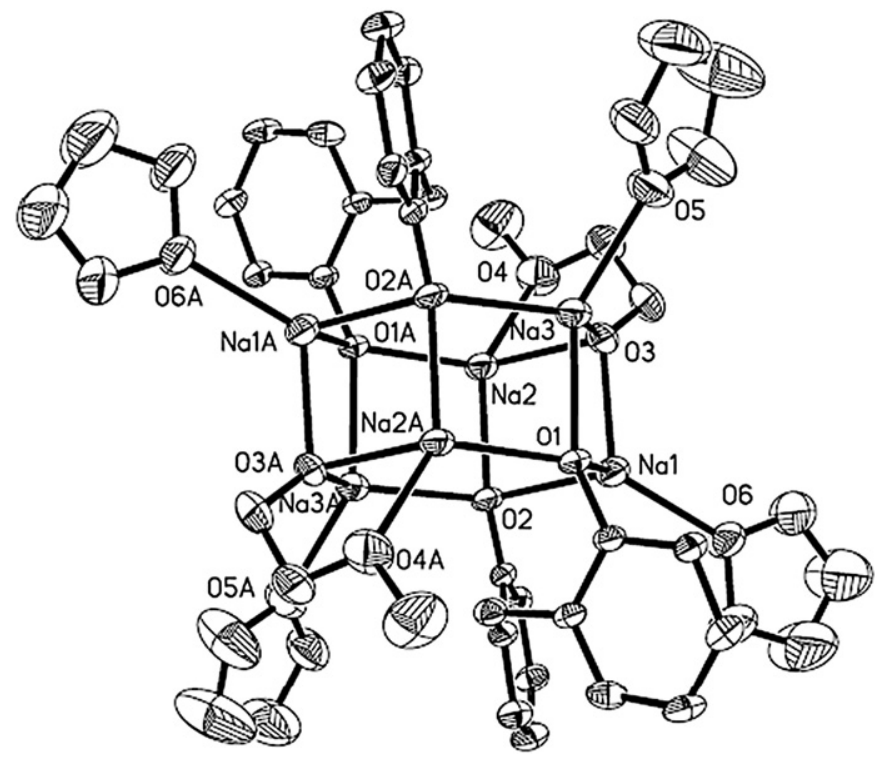

Fig. 1. Molecular structure of $\mathbf{1}$ as $30 \%$ ellipsoids (carbon atoms of the tert-butyl groups and all of the hydrogen atoms are omitted for clarity). Selected bond lengths $(\AA)$ : $\mathrm{Na} 1-012.330(6), \mathrm{Na} 1-\mathrm{O} 2$ 2.352(6), Na1-O3 2.241(5), Na1-O6 2.290(7), Na2-O2 2.264(5), Na2-O1A 2.279(5), Na2-O3 2.300(6), Na2-O4 2.305(7), Na3-O3 2.253(6), Na3-O5 2.344(7), Na3-O1A 2.355(5), Na3-O2 2.378(5) $\mathrm{Na}(1)-\mathrm{Na}(2)$ 3.105(3), $\mathrm{Na}(1)-\mathrm{Na}(3) 3.180(3), \mathrm{Na}(2)-\mathrm{Na}(3) 3.606(4)$. Symmetry codes: $-\mathrm{x}+1$, $-\mathrm{y},-\mathrm{z}+2$. and the $\mathrm{O}-\mathrm{Na} 2-\mathrm{O}$ bond angles varying from $76.3(2)$ to $139.19(19)^{\circ}$, respectively. The Na3 is four-coordinated with distorted tetrahedral coordination geometry by four oxygen atoms ( $01 \mathrm{~A}, 02,03$, and 05$)$ from three different ligands with bond lengths Na3-01 2.355(5), Na3-O2A 2.378(5), Na3-03 2.253(6) and Na3-05 2.344(7) Å, respectively. In addition, the asymmetric unit is linked into hexanuclear sodium aggregate by the asymmetric operation of inversion. The hexanuclear structure consists of two six-membered $\mathrm{Na}_{3} \mathrm{O}_{3}$ rings linked by six $\mathrm{Na}_{2} \mathrm{O}_{2}$ cores. In these rings, all of the six oxygen atoms $(01,02,03,01 \mathrm{~A}, 02 \mathrm{~A}$, and $\mathrm{O} 3 \mathrm{~A}$ ) are triply bridged.

Single crystals of $\mathbf{2}$ suitable for X-ray structural determination were obtained from a mixture THF and hexane solution at room temperature. Complex 2 crystallizes in monoclinic $P 2(1) / c$ space group. The asymmetric unit is composed of one independent $\mathrm{Na}$ center, one $\mathrm{MDBPH}^{-}$ligand, one aqua ligand, one coordinated THF, and one free THF molecule in a crystal lattice. As depicted in Fig. 2, there is one $\mathrm{Na}$ atom in the asymmetric unit of $\mathbf{2}$ with slightly distorted tetrahedral geometry. The Na1 is surrounded by one oxygen (01) atom from MDBPH ligand, one oxygen (O3) atom coordinated THF molecule, and two oxygen atoms (01W, and 01WA) from two aqua waters. The $\mathrm{Na}-\mathrm{O}$ bond distances are in the range of 2.356(3)-2.396(3) $\AA$, and the $\mathrm{O}-\mathrm{Na}-\mathrm{O}$ bond angles vary from $86.51(11)$ to $132.43(13)^{\circ}$. It is interestingly that the binuclear $\left[\mathrm{Na}\left(\mathrm{OH}_{2}\right)\right]_{2}$ unit with a $\mathrm{Na} \cdot \mathrm{Na}$ distance of 3.463(4) $\AA$ was formed through two $\mu_{2}-\mathrm{H}_{2} \mathrm{O}$ molecules to bridging two Na centers. In addition, there exist intramolecular hydrogen bond $(\mathrm{O} 1 \mathrm{~W}-\mathrm{H} \cdots \mathrm{O} 2)$ and intermolecular hydrogen bond $(01 \mathrm{~W}-\mathrm{H} \cdots \mathrm{0} 4)$. It is believed that the hydrogen-bonding interactions play an important role in the stabilization of complex $\mathbf{2}$.

Although many syntheses of sodium aggregates [11,12] have been reported, mixed-ligand sodium aggregates in ROP of lactide have barely received attention. In this paper, ROP of L-lactide employing 1 $(0.02 \mathrm{mmol})$ as initiator is systematically examined in toluene (40 mL) at $0{ }^{\circ} \mathrm{C}$ and $25{ }^{\circ} \mathrm{C}$ as shown in Table 1 . It was found that complex $\mathbf{1}$ is an efficient initiator for the ROP of L-lactide. ROP of lactide goes to completion within $0.5 \mathrm{~h}$ at room temperature (Table 1, entries 1 and 2 ), and the reaction rate decreases with decreasing of temperature (Table 1, entries 3-9). Comparing with other hetero-bimetallic bisphenol complexes, complex $\mathbf{1}$ shows a high activity for the ROP of L-LA under room temperature $[6,11,13]$. The polymerization time 


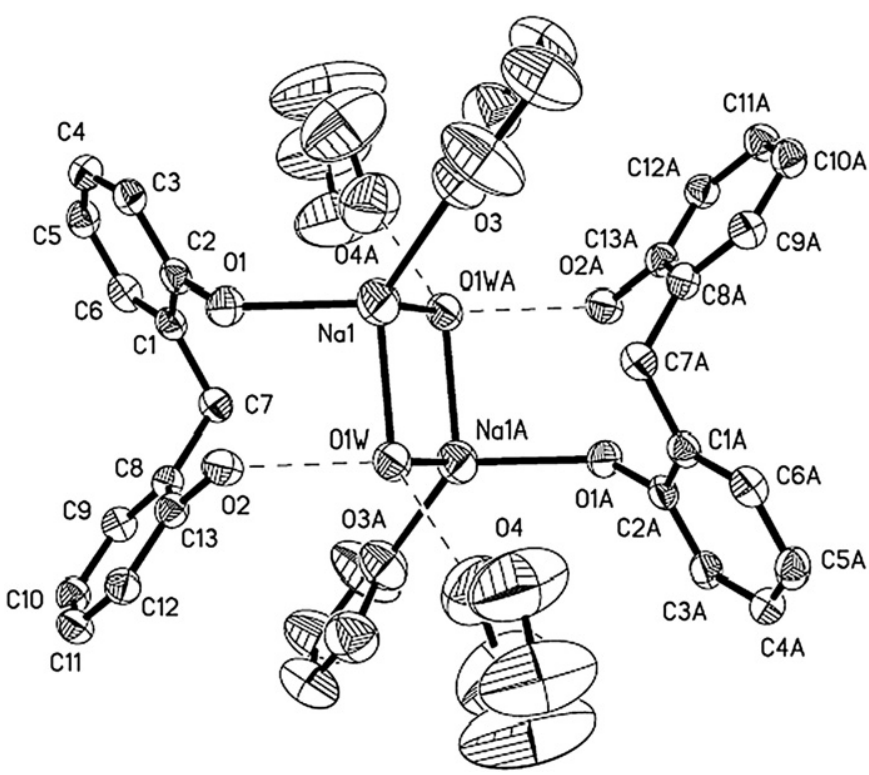

Fig. 2. Molecular structure of $\mathbf{2}$ as 35\% ellipsoids (carbon atoms of the tert-butyl groups and all of the hydrogen atoms are omitted for clarity). Selected bond lengths $(\AA)$ : Na1-O1 2.356(3), Na1-O1W 2.396(3), Na1-O3 2.370(4), Na1-O1WA 2.358(3), Na1-Na1A 3.463(4). Symmetry codes: $-x+1,-y+1,-z$.

required for the hexanuclear aggregate complex $\mathbf{1}$ is much shorter compared with the other dinuclear or tetranuclear sodium aggregates $[11,12]$. This may be attributed to the easily obtained oxygen anion of 2-methoxyethanol when complex $\mathbf{1}$ is in the toluene, which is an initiator in the anion ROP of L-lactide [14]. However, the polydispersity indexes (PDIs) of poly(L-lactide)s obtained at $0{ }^{\circ} \mathrm{C}$ are narrow, ranging from 1.38 to 1.44 , and a linear relationship between the numberaverage molecular weight $(\mathrm{Mn})$ and the monomer-to-initiator ratio $\left([\mathrm{M}]_{0} /[\mathrm{I}]_{0}\right)$ existed (Fig. 3 ), implying the controlled character of the polymerization process. It is worth noting that the ${ }^{1} \mathrm{H}$ NMR spectrum (Fig. 4) of PLA-100 shows one 2-methoxyethanolate group and one hydroxyl chain end, suggesting that the initiation occurs through the insertion of the alkoxy group from complex 1 into L-lactide and the backing reactions do not occur in our condition. This is further verified by the following experimental results. First, the homonuclear decoupled ${ }^{1} \mathrm{H}$ NMR spectrum (Fig. 5) reveals only one resonance at $\delta$ $5.16 \mathrm{ppm}$ in the methine region. Second, if cyclization occurs during polymerization, the PDIs of the resulting PLA would be much higher. However, the PDIs of the PLA obtained are in a narrow range. Furthermore, epimerization of the chiral centers in PLA does not occur as

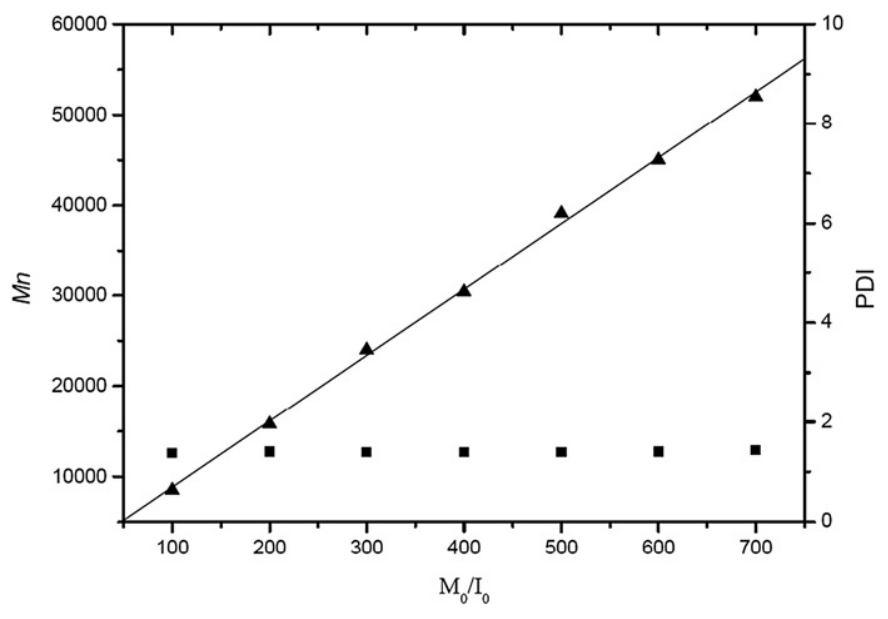

Fig. 3. Polymerization of L-LA catalyzed by 1 in toluene at $0{ }^{\circ} \mathrm{C}$. The relationship between $\operatorname{Mn}(\boldsymbol{\Lambda})\left(\mathrm{PDI}(\boldsymbol{\square})\right.$ ) of the polymer and the initial mole ratio $[\mathrm{M}]_{0} /[\mathrm{I}]_{0}$ is shown.

observed by the homonuclear decoupled ${ }^{1} \mathrm{H}$ NMR studies in the methine region [15]. In addition, the living character of the polymerization has been proved, which was further confirmed by our resumption experiment (Table 1, entry 10) in which another portion of L-LA monomer $\left([\mathrm{LA}]_{0} /[\mathrm{I}]_{0}=100\right)$ was added after the polymerization of the first addition $\left([\mathrm{LA}]_{0} /[\mathrm{I}]_{0}=100\right)$ had gone to completion.

In conclusion, there are two novel sodium complexes supported by bisphenol ligand that have been synthesized and fully characterized by spectroscopic methods as well as X-ray diffraction. Experimental results show that complex $\mathbf{1}$ is an efficient initiator for the ROP of lactide in controlled fashion, yielding polymers with expectative molecular weight and low polydispersity indexes.

\section{Acknowledgments}

We thank the National Natural Science Foundation of China (21171173, 21173246 and 21071069) and the "Hundred-talent Project" (KJCX2-YW-W34) of the Chinese Academy of Sciences for the financial support.

\section{Appendix A. Supplementary material}

CCDC 855790 and 860011 contain the supplementary crystallographic data for $\mathbf{1}$ and $\mathbf{2}$, respectively. These data can be obtained free of charge from The Cambridge Crystallographic Data Centre via www. ccdc.cam.ac.uk/data_request/cif. Supplementary data associated with

Table 1

Ring-opening polymerization of L-lactide initiated by $\mathbf{1}$.

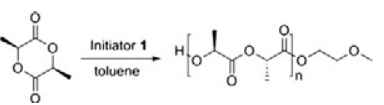

\begin{tabular}{|c|c|c|c|c|c|c|c|}
\hline Entry & {$[\mathrm{M}]_{0} /[\mathrm{I}]_{0}$} & Temperature $\left({ }^{\circ} \mathrm{C}\right)$ & Time $(\mathrm{h})$ & $\operatorname{Mn}(G P C)^{a}$ & Mn (calcd.) ${ }^{b}$ & PDI & Conversion (\%) \\
\hline 1 & $250: 1$ & 25 & 0.5 & $27,300(15,800)$ & 17,700 & 1.48 & 98 \\
\hline 2 & $300: 1$ & 25 & 0.5 & $35,200(20,400)$ & 21,000 & 1.43 & 97 \\
\hline 3 & $100: 1$ & 0 & 2 & $14,600(8500)$ & 7060 & 1.38 & 97 \\
\hline 4 & $200: 1$ & 0 & 2 & $27,300(15,800)$ & 13,900 & 1.40 & 96 \\
\hline 5 & $300: 1$ & 0 & 2 & $41,400(24,000)$ & 21,200 & 1.39 & 98 \\
\hline 6 & $400: 1$ & 0 & 3 & $52,400(30,400)$ & 27,700 & 1.39 & 96 \\
\hline 7 & $500: 1$ & 0 & 3 & $67,400(39,100)$ & 34,600 & 1.39 & 96 \\
\hline 8 & $600: 1$ & 0 & 3 & $77,600(45,000)$ & 41,100 & 1.40 & 95 \\
\hline 9 & $700: 1$ & 0 & 3 & $89,700(52,000)$ & 49,000 & 1.44 & 97 \\
\hline 10 & $100(100): 1^{d}$ & 0 & $2(2)$ & $26,400(15,300)$ & 14,100 & 1.45 & 98 \\
\hline
\end{tabular}

a Obtained from GPC analysis and calibrated by polystyrene standard. Values in parentheses are the values obtained from GPC times 0.58 [16].

b Calculated from the molecular weight of L-lactide times $[\mathrm{M}]_{0} / 2[\mathrm{I}]_{0}$ times conversion yield plus the molecular weight of 2-methoxyethanol.

c Obtained from ${ }^{1} \mathrm{H}$ NMR analysis.

d Prepolymerization of LA with 1 for $2 \mathrm{~h}$, followed by the addition of another portion of L-LA. 


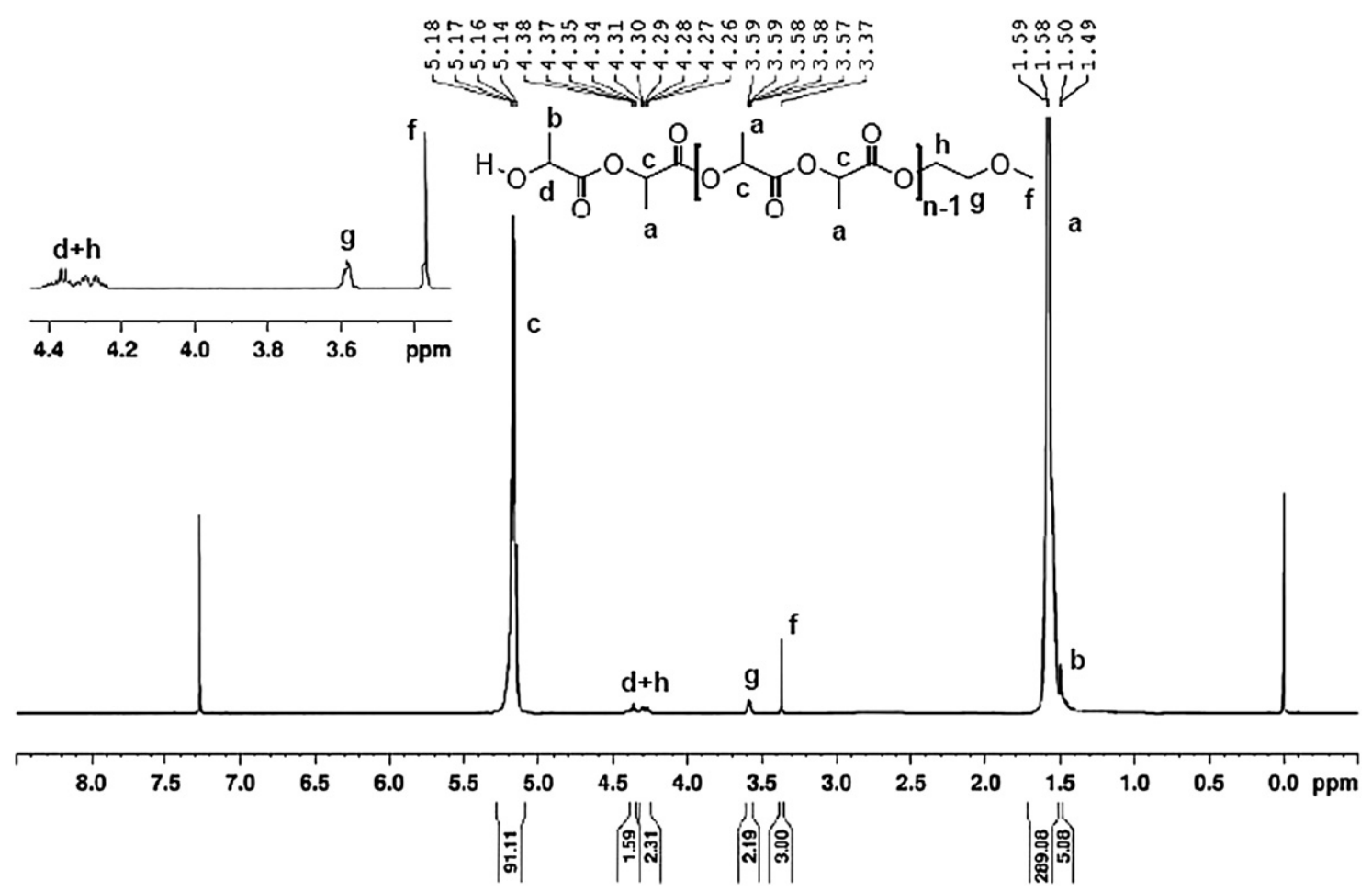

Fig. 4. ${ }^{1} \mathrm{H}$ NMR spectrum of PLA-100 initiated by complex 1.

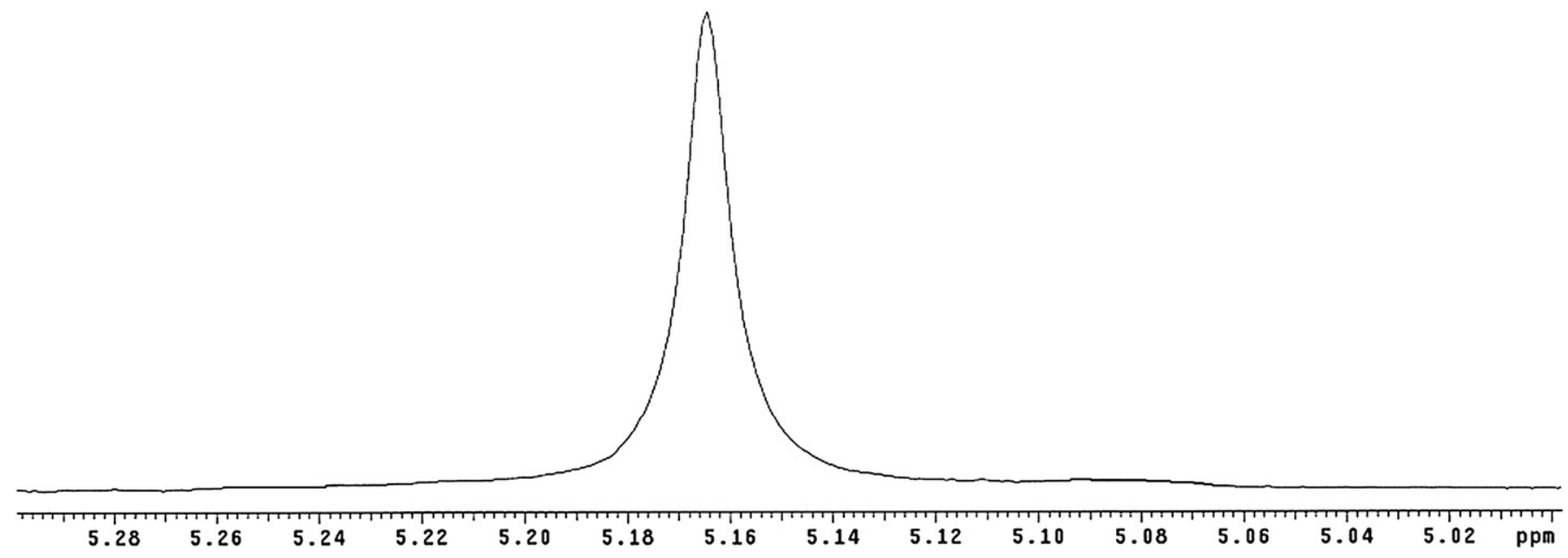

Fig. 5. Homonuclear decoupled ${ }^{1} \mathrm{H}$ NMR spectrum reveals only one resonance at $\delta 5.16 \mathrm{ppm}$ in the methane region in the polymer of PLLA-100.

this article can be found, in the online version, at http://dx.doi.org/10. 1016/j.inoche.2012.12.029.

\section{References}

[1] (a) E. Chiellini, R. Solaro, Biodegradable polymeric materials, Adv. Mater. 8 (1996) 305:

(b) K.E. Uhrich, S.M. Cannizzaro, R.S. Langer, K.M. Shakesheff, Polymeric systems for controlled drug release, Chem. Rev. 99 (1999) 3181;

(c) R.E. Drumright, P.R. Gruber, D.E. Henton, Polylactic acid technology, Adv. Mater. 12 (2000) 1841;

(d) R.P. Lanza, R. Langer, J. Vacanti, Principles of Tissue Engineering, 2nd ed. Academic Press, San Diego, CA, 2000.;

(e) K. Nakano, N. Kosaka, T. Hiyama, K. Nozaki, Metal-catalyzed synthesis of stereoregular polyketones, polyesters, and polycarbonates, J. Chem. Soc. Dalton Trans. (2003) 4039.

[2] (a) B.J. O' Keefe, M.A. Hillmyer, W.B. Tolman, Polymerization of lactide and related cyclic esters by discrete metal complexes, J. Chem. Soc. Dalton Trans. (2001) 2215; (b) M.S. Lindblad, Y. Liu, A.C. Albertsson, E. Ranucci, S. Karlsson, Polymers from renewable resources, Adv. Polym. Sci. 157 (2002) 139;

(c) O. Dechy-Cabaret, B. Martin-Vaca, D. Bourissou, Controlled ring-opening polymerization of lactide and glycolide, Chem. Rev. 104 (2004) 6147;

(d) J. Wu, T.-L. Yu, C.-T. Chen, C.-C. Lin, Recent developments in main group metal complexes catalyzed/initiated polymerization of lactides and related cyclic esters, Coord. Chem. Rev. 250 (2006) 602.

[3] (a) R.C. Yu, C.H. Hung, J.H. Huang, H.Y. Lee, J.T. Chen, Four- and five-coordinate aluminum ketiminate complexes: synthesis, characterization, and ring-opening polymerization, Inorg. Chem. 41 (2002) 6450;

(b) L.F. Sánchez-Barba, A. Garcés, M. Fajardo, C. Alonso-Moreno, J. Fernández-Baeza, A. Otero, A. Antiñolo, J. Tejeda, A. Lara-Sánchez, M.I. López-Solera, Well-defined alkyl heteroscorpionate magnesium complexes as excellent initiators for the ROP of cyclic esters, Organometallics 26 (2007) 6403;

(c) H.Z. Du, A.H. Velders, P.J. Dijkstra, Z.Y. Zhong, X.S. Chen, J. Feijen, Polymerization of lactide using achiral bis(pyrrolidene) schiff base aluminum complexes, Macromolecules 42 (2009) 1058;

(d) N. Iwasa, S. Katao, J. Liu, M. Fujiki, Y. Furukawa, K. Nomura, Notable effect of fluoro substituents in the imino group in ring-opening polymerization of $\varepsilon$-caprolactone by $\mathrm{Al}$ complexes containing phenoxyimine ligands, Organometallics 28 (2009) 2179. 
[4] (a) D. Chakraborty, E.Y.X. Chen, Neutral, three-coordinate, chelating diamide aluminum complexes: catalysts/initiators for synthesis of telechelic oligomers and high polymers, Organometallics 21 (2002) 1438;

(b) D.J. Darensbourg, W. Choi, O. Karroonnirun, N. Bhuvanesh, Ring-opening polymerization of cyclic monomers by complexes derived from biocompatible metals. Production of poly(lactide), poly(trimethylene carbonate), and their copolymers, Macromolecules 41 (2008) 3493;

(c) N. Nimitsiriwat, V.C. Gibson, E.L. Marshall, M.R.J. Elsegood, The reversible amination of Tin(II)-ligated imines: latent initiators for the polymerization of rac-lactide, Inorg. Chem. 47 (2008) 5417;

(d) Z. Zheng, G. Zhao, R. Fablet, M. Bouyahyi, C.M. Thomas, T. Roisnel, O. Casagrande Jr., J.F. Carpentier, Zinc and enolato-magnesium complexes based on bi-, tri- and tetradentate aminophenolate ligands, New J. Chem. 32 (2008) 2279;

(e) G. Labourdette, D.J. Lee, B.O. Patrick, M.B. Ezhova, P. Mehrkhodavandi, Unusually stable chiral ethyl zinc complexes: reactivity and polymerization of lactide, Organometallics 28 (2009) 1309;

(f) J. Börner, I. dos S. Vieira, M.D. Jones, A. Döring, D. Kuckling, U. Flörke, S. Herres-Pawlis, Zinc complexes with guanidine-pyridine hybrid ligandsguanidine effect and catalytic activity, Eur. J. Inorg. Chem. (2011) 4441;

(g) J. Koller, R.G. Bergman, Highly efficient aluminum-catalyzed ring-opening polymerization of cyclic carbonates, lactones, and lactides, including a unique crystallographic snapshot of an intermediate, Organometallics 30 (2011) 3217.

[5] C.H. Huang, F.C. Wang, B.T. Ko, T.L. Yu, C.-C. Lin, Ring-opening polymerization of $\varepsilon$-caprolactone and L-lactide using aluminum thiolates as initiator, Macromolecules 34 (2001) 356

[6] (a) M.H. Chisholm, J.C. Gallucci, H.S. Zhen, Three-coordinate zinc amide and phenoxide complexes supported by a bulky schiff base ligand, Inorg. Chem. 40 (2001) 5051:

(b) L. Wang, X.B. Pan, L.H. Yao, N. Tang J.C. Wu, Ring-opening polymerization of L-lactides catalyzed by zinc-sodium/lithium heterobimetallic complexes in the presence of water, Eur. J. Inorg. Chem. (2011) 632;

(c) X.B. Pan, X.Z. Yang, L.H. Chen, J.C. Wu, N. Tang, Synthesis and characterization of hetero-bimetallic aryloxides and application in the polymerization of lactides, Inorg. Chem. Commun. 13 (2010) 919.

[7] Many alkoxides have been reported to initiate ROP of lactide, and been review in reference [2]. Some selective papers are shown as following: (a). P.A. Cameron, D. Jhurry, V.C. Gibson, A.J.P. White, D.J. Williams, S. Williams, Controlled polymerization of lactides at ambient temperature using [5-Cl-salen]AlOMe, Macromol Rapid Commun. 20 (1999) 616;

(b) B.M. Chamberlain, M. Cheng, D.R. Moore, T.M. Ovitt, E.B. Lobkovsky, G.W. Coates, Polymerization of Lactide with Zinc and Magnesium $\beta$-Diiminate Complexes: Stereocontrol and Mechanism, J. Am. Chem. Soc. 123 (2001) 3229;

(c) M.H. Chisholm, J. Gallucci, K. Phomphrai, Coordination Chemistry and Reactivity of Monomeric Alkoxides and Amides of Magnesium and Zinc Supported by the Diiminato Ligand $\mathrm{CH}\left(\mathrm{CMeNC}_{6} \mathrm{H}_{3}-2,6-{ }^{\mathrm{i}} \mathrm{Pr}_{2}\right)_{2}$. A Comparative Study, Inorg. Chem 41 (2002) 2785:

(d) Z. Zhong, P.J. Dijkstra, J. Feijen, Controlled and Stereoselective Polymerization of Lactide: Kinetics, Selectivity, and Microstructures, J. Am. Chem. Soc. 125 (2003) 11291;

(e) C.K. Williams, L.E. Breyfrogle, S.K. Choi, W. Nam, V.G. Young Jr., M.A. Hillmyer, W.B. Tolman, A Highly Active Zinc Catalyst for the Controlled Polymerization of Lactide, J. Am. Chem. Soc. 125 (2003) 11350;

(f) L.E. Breyfogle, C.K. Williams, V.G. Young Jr., M.A. Hillmyer, W.B. Tolman, Comparison of structurally analogous $\mathrm{Zn}_{2}, \mathrm{Co}_{2}$, and $\mathrm{Mg}_{2}$ catalysts for the polymerization of cyclic esters, Dalton Trans. (2006) 928;

(h) H.Y. Tang, H.Y. Chen, J.H. Huang, C.-C. Lin, Synthesis and Structural Characterization of Magnesium Ketiminate Complexes: Efficient Initiators for the Ring-Opening Polymerization of l-Lactide, Macromolecules 40 (2007) 8855;

(i) M.H. Chisholm, J.C. Gallucci, K.T. Quisenberry, Z. Zhou, Complexities in the Ring-Opening Polymerization of Lactide by Chiral Salen Aluminum Initiators, Inorg. Chem. 47 (2008) 2613;

(j) X. Pang, X. Chen, X. Zhuang, X. Jing, Crown-like macrocycle zinc complex derived from $\beta$-diketone ligand for the polymerization of rac-lactide, J. Polym. Sci., Part A: Polym. Chem. 46 (2008) 643;

(k) F.M. Marcin, A. Duda, Effect of the Configuration of the Active Center on Comonomer Reactivities: The Case of $\varepsilon$-Caprolactone/l,l-Lactide Copolymerization, Angew. Chem., Int. Ed. 47 (2008) 9088;

(m) J. Ejfler, S. Szafert, K. Mierzwicki, L.B. Jerzykiewicz, P. Sobota, Homo- and heteroleptic zinc aminophenolates as initiators for lactide polymerization, Dalton Trans. (2008) 6556;

(n) M. Bouyahyi, E. Grunova, N. Marquet, E. Kirillov, C.M. Thomas, T. Roisnel, J.F. Carpentier, Aluminum Complexes of Fluorinated Dialkoxy-Diimino Salen-like Ligands: Syntheses, Structures, and Use in Ring-Opening Polymerization of $\mathrm{Cy}$ clic Esters, Organometallics 27 (2008) 5815

(o) W.C. Hung, C.-C. Lin, Preparation, Characterization, and Catalytic Studies of Magnesium Complexes Supported by NNO-Tridentate Schiff-Base Ligands, Inorg. Chem. 48 (2009) 728.

[8] (a) Y. Ning, A. Zhang, E.Y.X. Rodriguez-Delgado, Neutral metallocene ester enolate and non-metallocene alkoxy complexes of zirconium for catalytic ring-opening polymerization of cyclic esters, Organometallics 27 (2008) 5632 ; (b) Y.-C. Chen, C.-Y. Lin, W.-Y. Huang, A. Datta, J.-H. Huang, M.-S. Tsai, T.-Y. Lee, C.-Y. Tu, C.-H. Hu, Reactions of dimeric aluminium hydride compounds containing bidentate dianionic pyrrolyl ligands and their applications in ring-opening polymerization of -caprolactone, Eur. J. Inorg. Chem. (2011) 2459.

[9] (a) H. Ma, J. Okuda, Kinetics and mechanism of L-lactide polymerization by rare earth metal silylamido complexes: effect of alcohol addition, Macromolecules 38 (2005) 2665;

(b) R.H. Platel, A.J.P. White, C.K. Williams, A series of bis(phosphinic)diamido yttrium complexes as initiators for lactide polymerization, Inorg. Chem. 47 (2008) 6840 ;

(c) F. Chen, W. Zhu, N. Xu, Z. Shen, Ring-opening copolymerization of ethylene carbonate and $\varepsilon$-caprolactone catalyzed by neodymium tris(2,6-di-tert-butyl4-methylphenolate): synthesis, characterization, and dynamic mechanic analysis, J. Polym. Sci. A Polym. Chem. 46 (2008) 4050;

(d) W. Gao, D. Cui, X. Liu, Y. Zhang, Y. Mu, Rare-earth metal bis(alkyl)s supported by a quinolinyl anilido-imine ligand: synthesis and catalysis on living polymerization of $\varepsilon$-caprolactone, Organometallics 27 (2008) 5889;

(e) M. Xue, R. Jiao, Y. Zhang, Y. Yao, Q. Shen, Syntheses and structures of tris- $\beta-$ diketiminate lanthanide complexes and their high activity for ring-opening polymerization of -caprolactone and L-lactide, Eur. J. Inorg. Chem. (2009) 4110;

(f) A. Otero, J. Fernández-Baeza, A. Lara-Sánchez, C. Alonso-Moreno, I. MárquezSegovia, L.F. Sánchez-Barba, A.M. Rodríguez, Ring-opening polymerization of cyclic esters by an enantiopure heteroscorpionate rare earth initiator, Angew. Chem. Int. Ed. 48 (2009) 2176

(g) J.W. Kramer, D.S. Treitler, E.W. Dunn, P.M. Castro, T. Roisnel, C.M. Thomas, G.W. Coates, Polymerization of enantiopure monomers using syndiospecific catalysts: a new approach to sequence control in polymer synthesis, J. Am. Chem. Soc. 131 (2009) 16042.

(h) H.E. Dyer, S. Huijser, N. Susperregui, F. Bonnet, A.D. Schwarz, R. Duchateau, L. Maron, P. Mountford, Ring-opening polymerization of rac-lactide by bis(phenolate)amine-supported samarium borohydride complexes: an experimental and DFT study, Organometallics 29 (2010) 3602

(i) M. Oshimura, A. Takasu, Controlled ring-opening polymerization of $\varepsilon$ caprolactone catalyzed by rare-earth perfluoroalkanesulfonates and perfluoroalkanesulfonimides, Macromolecules 43 (2010) 2283;

(j) M. Sinenkov, E. Kirillov, T. Roisnel, G. Fukin, A. Trifonov, J.-F. Carpentier, Rareearth complexes with multidentate tethered phenoxy-amidinate ligands: synthesis, structure, and activity in ring-opening polymerization of lactide, Organometallics 30 (2011) 5509;

(k) C. Iftner, F. Bonnet, F. Nief, M. Visseaux, L. Maron, Mechanistic insights of the initiation process of the ring-opening polymerization of $\varepsilon$-caprolactone by divalent $\mathrm{Sm}\left(\mathrm{BH}_{4}\right)_{2}(\mathrm{THF})_{2}$ with DFT: concerted or oxidative reaction? Organometallics 30 (2011) 4482.

[10] Percentages by mass, in: J. Emsley (Ed.), The Elements, Clarendon Press, Oxford, 1998, p. 194.

[11] (a) H.-Y. Chen, J. Zhang, C.-C. Lin, J.H. Reibenspies, S.A. Miller, Efficient and controlled polymerization of lactide under mild conditions with a sodiumbased catalyst, Green Chem. 9 (2007) 1038;

(b) Y. Huang, Y.-H. Tsai, W.-C. Hung C.-S. Lin, W. Wang. J-H. Huang S. Dutta, C.-C. Lin, Synthesis and structural studies of lithium and sodium complexes with OOO-tridentate Bis(phenolate) ligands: effective catalysts for the ring-opening polymerization of L-lactide, Inorg. Chem. 49 (2010) 9416;

(c) B. Calvo, M.G. Davidson, D. García-Vivó, Polyamine-stabilized sodium aryloxides: simple initiators for the ring-opening polymerization of rac-lactide, Inorg. Chem. 50 (2011) 3589;

(d) L.H. Yao, L. Wang, X.B. Pan, N. Tang, J.C. Wu, Synthesis, characterization and catalytic activity of Salen-( sodium $)_{2}$ and (Salen) $)_{2}$-lanthanum-sodium complexes, Inorg. Chim. Acta 373 (2011) 219-225.

12] (a) M.B. Dinger, M.J. Scott, Selective binding of substrates using sodium salts of linked C3 symmetric aryl oxides, Chem. Commun. (1999) 2525;

(b) M.B. Dinger, M.J. Scott, Alkali salts of C3-symmetric, linked aryloxides: selective binding of substrates with metal aggregates, Inorg. Chem. 39 (2000) 1238.

[13] X.B. Pan, A. Liu, X.Z. Yang, J.C. Wu, N. Tang, Synthesis, characterization of potassium bulky phenolate and application in ring-opening polymerization of L-lactide, Inorg. Chem. Commun. 13 (2010) 376

[14] (a) A. Bhaw-Luximon, D. Jhurry, N. Spassky, S. Pensec, J. Belleney, Anionic polymerization of D, L-lactide initiated by lithium diisopropylamide, Polymer 42 (2001) 9651;

(b) A.K. Sutar, T. Maharana, S. Dutta, C.-T. Chen, C.-C. Lin, Ring-opening polymerization by lithium catalysts: an overview, Chem. Soc. Rev. 39 (2010) 1724

[15] K.A.M. Thakur, R.T. Kean, E.S. Hall, J.J. Kolstad, T.A. Lindgren, M.A. Doscotch, J.I. Siepmann, E.J. Munson, High-resolution ${ }^{13} \mathrm{C}$ and ${ }^{1} \mathrm{H}$ solution NMR study of poly(lactide), Macromolecules 30 (1997) 2422.

[16] The $\mathrm{Mn}(\mathrm{GPC})$ is multiplied by a factor of 0.58 , giving the actual Mn of polylactide. J. Baran, A. Duda, A. Kowalski, R. Szymanski, S. Penczek, Intermolecular chain transfer to polymer with chain scission: general treatment and determination of $k_{\mathrm{p}} / k_{\mathrm{tr}}$ in L,L-lactide polymerization, Macromol. Rapid Commun. 18 (1997) 325. 